\title{
Decrease in Life Expectancy in Germany in 2020: Men from Eastern Germany Most Affected
}

\author{
Marc Luy, Markus Sauerberg, Magdalena Muszyńska-Spielauer, \\ Vanessa di Lego
}

\begin{abstract}
The COVID-19 pandemic caused an increase in mortality in 2020 with a resultant decrease in life expectancy in most countries around the world. In Germany, the reduction in life expectancy at birth between 2019 and 2020 was comparatively small, at -0.20 years. The decrease was stronger among men than among women (-0.24 vs. -0.13 years) and in eastern rather than in western Germany (-0.36 vs. -0.16 years). Men in eastern Germany experienced the biggest decline in life expectancy at birth $(-0.41$ years). For western German men, the decline was less pronounced (-0.19 years). Among women, the decline in life expectancy at birth was also greater in eastern ( -0.25 years) than in western Germany (-0.10 years). As a result of these developments, the differences in life expectancy between the two parts of Germany, and between women and men, increased compared with the previous year. Life expectancy at age 65 decreased more strongly than life expectancy at birth for both sexes and in all regions. This reflects the fact that it was mainly older age groups that were affected by the increase in mortality in 2020. This paper provides further insights into mortality changes in 2020, based on age decomposition and an analysis of lifespan inequality. We conclude that the population in eastern Germany was hit harder by the COVID-19 pandemic in 2020 than the population in the western Germany.
\end{abstract}

Keywords: Life expectancy · Lifespan inequality - Mortality - COVID-19 - Germany · Eastern Germany · Western Germany · West-east difference $\cdot$ Gender difference 


\section{Introduction}

The COVID-19 pandemic changed human life significantly in 2020, affecting all populations around the globe and leading to increases in human mortality in many parts of the world. In Germany, the first cases of death related to the COVID-19 pandemic were reported at the beginning of March 2020. As the virus continued to spread, not only in Germany but also worldwide, researchers began investigating the impact of COVID-19 on mortality. Since there is no uniform way of classifying, recording, and reporting COVID-19 deaths (Karanikolos et al. 2020), and because the number of reported COVID-19 cases is affected by individual countries' testing capacity, scholars have focused on comparing the total number of deaths observed in the current period, i.e. deaths from all causes, with death counts observed in previous periods (Ghislandi et al. 2021; Beaney et al. 2020; Vandoros 2020). In this way, it is possible to assess the extent to which the observed number of deaths in a given period - e.g. in a calendar week or year - is unexpected in relation to the previous year(s). This is also referred to as "excess deaths".

Previous studies have found that Germany did indeed experience excess mortality during the COVID-19 pandemic. Furthermore, it has been shown that excess deaths in Germany are not distributed uniformly over time, age, and regions (Zur Nieden/ Engelhard 2021; Sauerberg 2021). For instance, the largest number of excess deaths occurred in the final calendar weeks of 2020, with particularly high levels observed in eastern Germany. ${ }^{1}$ It has also been documented that, in Germany and in other countries, excess mortality has been generally higher among older individuals and that men tend to show a higher risk of dying as a result of COVID-19 than women (Islam et al. 2021; Kontis et al. 2020; Gebhard et al. 2020; Bhopal/Bhopal 2020).

The metric of excess deaths provides useful information about exceptional changes in death counts. Yet, the extent to which the increase in mortality is exceptional is difficult to assess from these numbers. An intuitively more accessible number is the resulting change in period life expectancy (LE). It connects a set of age-specific death rates observed in a given period and summarises them in terms of the average number of life years that would be lived in the population under current death rates. Accordingly, an increase or decrease in LE can be directly ascribed to changes in age-specific death rates. It should be noted, however, that comparisons based on mortality count measures both before and during the pandemic and statistics of excess deaths, and changes in LE might be impacted by any additional temporary external shocks to mortality in the study period, e.g. heat waves in the summer or influenza epidemics in the winter. For example, the interventions to contain the spread of SARS-CoV-2 might have actually reduced the spread of influenza in 2020 and hence resulted in lower death rates from this cause in 2020 than in 2019, as suggested by recent reports showing that influenza viruses were at historic low levels in 2021 (O/sen et al. 2021). As a result, the excess mortality

1 See "death counts by calendar week" for each state in Germany. Available at https://service. destatis.de/DE/bevoelkerung/sterbefallzahlen_bundeslaender.html. 
in 2020 , as compared with 2019, might have been higher than the observed figures if the spread of influenza had not been reduced by non-pharmaceutical measures such as lockdowns and social distancing.

Several studies have used LE to assess the impact of COVID-19 on mortality in European countries such as Italy, Sweden, Spain, and the UK (Ghislandi et al. 2021; Modig et al. 2020; Trias-Llimós et al. 2020; Aburto et al. 2021a). Estimates for Europe revealed that the extent of changes in LE in 2020 compared with 2019 is very heterogeneous, ranging from a considerable decrease of -1.6 years in Spain to an increase of +0.3 years in Norway (see Eurostat 2021). As of the beginning of September 2021, we had found three publications with information on changes in LE in Germany. The first stems from the Federal Statistical Office of Germany, which published life tables with corresponding LE estimates for the periods 2017-2019 and 2018-2020 (Statistisches Bundesamt 2021). However, the aggregation of three calendar years makes it difficult to assess the impact of COVID-19 on LE because the pandemic only started in 2020. The increases in mortality in 2020 are compensated by decreasing mortality in previous years which meant that LE remained more or less constant between the two periods 2017-19 and 2018-20 (+0.04 years for women and +0.01 years for men).

The abovementioned data from Eurostat (2021) includes LE figures for Germany for single calendar years up to 2020. They report that LE has decreased by -0.2 years between 2019 and 2020 for the population of Germany as a whole. Yet, the database of these estimates is limited. First, the number of deaths includes both sexes combined, which prevents a gender-specific view of the changes. Second, the data from which LE is calculated is only divided into broad age intervals, i.e. in 10 -year age groups below age 40 , in 5 -year age groups for ages 40 to 84 , and $85+$ as the last open age interval (Eurostat 2021). This might bias the LE values because the indicator is particularly sensitive to changes in death rates at very young ages. In addition, the starting age of the last open age interval might be too low because deaths related to COVID-19 have occurred predominantly in older age groups. Thus, changes in old age mortality between 2019 and 2020 might not be fully taken into account.

Finally, Aburto et al. (2021b) estimated LE reductions in 2020 for several countries, including Germany. Their data stems from the "Short-term Mortality Fluctuations" (STMF) data series provided by the Human Mortality Database (HMD 2021). In the case of Germany, data refers to weekly death counts from 2016 onwards which are available by sex and 5-year age groups (except for the first age group 0-29), with 95+ being the last open age interval. Aburto et al. (2021b) used a penalised composite link model (PCLM) to obtain single age-specific death counts from age 0 to 110 from the grouped data. According to their estimates, LE in Germany decreased in 2020 by -0.23 years among women and -0.38 years among men.

All of these estimates suggest that the impacts of the COVID-19 pandemic on LE were much smaller in Germany than in most of the other countries. The aim of our paper is to extend the knowledge presented to date on changes in LE in Germany in 2020 by breaking the German population down into the regions of eastern and western Germany, based on their former borders. Even 30 years on 
from reunification, the two parts of the country continue to experience differences in many aspects, including population health and health care. ${ }^{2}$ Among men, the gap in LE at birth is still more than one year in favour of western Germany (Grigoriev et al. 2021). ${ }^{3}$ Although the gap between eastern and western Germany seemed to have vanished among women, the differences in living conditions that continue to prevail might have resulted in the COVID-19 pandemic affecting both sexes in different ways. In addition to presenting the changes in LE at birth and at age 65 for eastern and western Germany, we decompose the differences in LE between 2019 and 2020 by age to see whether the changes in LE were caused by similar or different changes in age-specific mortality of women and men in the two German regions. As we know from previous studies, the mortality increase observed in 2020 was of a different magnitude for young and old age groups, reinforcing the importance of capturing the role of specific ages in the observed mortality changes. Finally, we evaluate whether changes in LE were accompanied by an increase or decrease in lifespan inequality and if the direction and magnitude of the changes were the same for both regions. It is worth mentioning the biggest challenge of this study, namely to estimate LE separately for eastern and western Germany, because the necessary data had to be reconstructed from the statistical material that was available and provided by the Federal Statistical Office. This cannot be done without a number of assumptions and approximations which will be explained in detail in the subsequent section on data and methods. After presenting the results of our analyses, we will summarise and discuss them in the final section, focusing in particular on the different impact of the COVID-19 pandemic on LE in eastern and western Germany.

\section{Data and methods}

The analyses that are presented are based on life tables for different regions, namely western Germany (reflecting the geographical area of the former Federal Republic of Germany, FRG), eastern Germany (reflecting the geographical area of the former German Democratic Republic, GDR) and Germany as a whole, resulting from the sum of western and eastern Germany. ${ }^{4}$ The calculations are based on ageand sex-specific numbers of deaths and the living population (population at risk) for single calendar years provided by the Federal Statistical Office (Statistisches Bundesamt). Because the Federal Statistical Office stopped producing statistics for

2 See the recent "Spiegel" article about health inequalities between eastern and western Germany 30 years on from reunification, for example. Available at: https://www.spiegel.de/ gesundheit/diagnose/30-jahre-mauerfall-so-unterscheidet-sich-die-gesundheit-in-west-undost-a-1288102.html.

3 See also the time series of differences in life expectancy between western and eastern Germany at https://lebenserwartung.info.

4 We update and publish these data with corresponding statistics on life expectancy in Germany regularly on the website https://lebenserwartung.info. 
the geographical areas of the former FRG and GDR in 2000, we had to derive these numbers from the statistics available.

For the population at risk, we used the age- and sex-specific average population for single ages from $0-99$ and the last open age interval of $100+$, as provided by the Federal Statistical Office. These data related to Germany as a whole, western Germany excluding Berlin and eastern Germany excluding Berlin. Until 2012, the data on the living population is based on a forward projection of the censuses of 1981 in former East Germany and 1987 in former West Germany (intercensal population updates). Since 2013, the data is based on the forward projection of the census in 2011. Note that unlike previous censuses in Germany, the census in 2011 was not carried out as a traditional census in which all residents are counted and the heads of all households are interviewed. Instead, only a sample of households was interviewed and most of the data was collected from registers of administrative authorities, like the residents' registration offices, and the registers from the German Federal Employment Agency. ${ }^{5}$ As a consequence, the total population numbers result from extrapolations which leads to decimal numbers in the population counts and, accordingly, to rounding deviations between the official total and aggregated total population numbers.

In a first step, we used the data from the Federal Statistical Office to derive the age- and sex-specific average population for Berlin by subtracting the data for western and eastern Germany excluding Berlin from the data for the total population of Germany. We then subdivided the population of Berlin into former West and East Berlin on the basis of the average total population numbers for the twelve districts of Berlin as published annually by the Statistical Office of Berlin and Brandenburg (Amt für Statistik Berlin-Brandenburg), derived for a year $t$ from the published population stocks on 31 December of the years t-1 and t. The districts of Charlottenburg-Wilmersdorf, Spandau, Steglitz-Zehlendorf, Neukölln and Reinickendorf were assigned in their entirety to West Berlin, and the districts of Pankow, Tempelhof-Schönefeld, Treptow-Köpenick, Marzahn-Hellersdorf and Lichtenberg to East Berlin. The districts of Mitte and Friedrichshein-Kreuzberg cover territories of both former German states and were assigned equally (50:50) to the populations of West and East Berlin. Figure A1 in the appendix shows the resulting proportions of the estimated total average populations of West and East Berlin which were in turn used as weights to assign the population of Berlin accordingly to western and eastern Germany. Because a further separation of the data for the districts of Berlin by age and sex was not available for each calendar year, we used the weights for the total populations of West and East Berlin for each age and sex group. Finally, we constructed the age- and sex-specific populations of western Germany (former FRG) and eastern Germany (former GDR) by adding the estimated population numbers of West and East Berlin to the statistical office data for western Germany excluding Berlin and for eastern Germany excluding Berlin accordingly.

5 For details, see https://www.zensus2011.de. 
Information about deaths was available with the same specifications as the data for the average population until 2017, i.e. age- and sex-specific number of deaths for single ages from ages $0-99$ and the last open age interval of 100+, available for Germany as a whole, western Germany excluding Berlin and eastern Germany excluding Berlin. These data were assigned to the geographical areas of the former FRG and GDR using the same strategy as described above for the living population, and with the same weights for East and West Berlin as derived from the population data for the districts of Berlin. Since 2018, however, the Federal Statistical Office no longer provides data relating to deaths with the same structure and details. Data for single ages is now provided for Germany as a whole, western Germany excluding Berlin and eastern Germany including Berlin; this prevents the derivation of data for Berlin. Moreover, for confidentiality purposes, the only data made available is for ages with a certain minimum number of deaths. Therefore, we used the available data for deaths by broader age groups for the 16 German states and derived the numbers for western Germany excluding Berlin, eastern Germany excluding Berlin and for Berlin for these broader age intervals. Because of the confidentiality issue, the extent of the age intervals differs between sexes and calendar years: the age group 0-1 remained a single-year age group in all calendar years, but the following interval from age 1 differs in its extent, being 1-19 in 2018, 1-34 in 2019, and 1-29 in 2020. The remaining ages were grouped into 5 -year intervals up to the age group 95-99 and $100+$ as the last open age interval. We estimated the proportion of deaths for western Germany excluding Berlin, eastern Germany excluding Berlin and for Berlin for each available age interval, and separated by sex. These proportions were then applied to the number of deaths by single ages for the total female and male populations of Germany, e.g. for 2020, the weight for the age interval 1-29 for the single ages 1-29, the weight for the age group 30-34 for the single ages 30-34, and so forth. The final allocation to the geographic units western Germany (former FRG) and eastern Germany (former GDR) was made as described above for the living population and for deaths until 2017.

Although these restrictions in the information available on deaths in Germany increased the extent of assumptions, we are confident that the estimated ageand sex-specific numbers of death for eastern and western Germany are good approximations. Figure A2 in the appendix shows the trends in the relative number of deaths for women and men in western and eastern Germany from 2001 to 2020, summarised for the age groups $0-29,30-64$ and $65+$. The graphs reveal that the changes in the estimation strategy in 2017 do not lead to any break in the time trends.

The life tables for women and men of western Germany, eastern Germany and Germany as a whole were calculated using the standard demographic methodology, based on the age- and sex-specific death rates for single ages 0-99 and the last open age interval $100+$ for single calendar years (see, for example, Preston et al. 2001). Changes in LE between 2019 and 2020 were decomposed into age-specific contributions with the decomposition method proposed by Arriaga (1984). The method allows the contribution of each age (group) to the difference in LE to be calculated, i.e. decreases or increases in age-specific mortality will lead to either 
positive or negative contributions and the sum across all age-specific contributions is equal to the overall change in LE. More details about the decomposition method and the corresponding equations can be found in Preston et al. (2001).

In addition to investigating patterns and changes in LE, we also examine changes in lifespan inequality, measured here by the e-dagger indicator (Shkolnikov et al. 2011; Vaupe//Canudas-Romo 2003). While LE reflects the average lifespan duration, lifespan inequality focuses on differences between individuals in the duration of life. When studying age at death distributions over calendar time or comparing populations, the inclusion of lifespan inequality in addition to the LE indicator allows for a deeper understanding of how differences in mortality, or changes over the calendar time, are distributed across different age-groups. For example, it has been demonstrated that a rise in LE can be accompanied by either an increase or a decrease in lifespan inequality, depending on which age groups benefit most from the mortality decline (Vaupel et al. 2011; Van Raalte/Caswell 2013; Zhang/Vaupel 2009). The same applies to a reduction in LE: it can be accompanied by an increase (Vigezzi et al. 2021) or a decrease (Aburto et al. 2021a) in lifespan inequality. Once again, the effect depends on the ages at which most of the increase in mortality occurs.

\section{$3 \quad$ Results}

In 2020, LE at birth was 81.01 years for the population of Germany as a whole $(83.43$ years for women and 78.60 years for men). Compared with the previous year, LE decreased by -0.20 years in the population as a whole (Table 1). The decrease was greater for men than for women $(-0.24$ vs. -0.13 years), and it was stronger in eastern than in western Germany (-0.36 vs. -0.16 years). The biggest decrease in LE among all of the subpopulations that were considered was experienced by men in eastern Germany (-0.41 years). For men in western Germany, the decline in LE was less pronounced (-0.19 years). Among women, the decline in LE was also greater in former East Germany than in former West Germany: -0.25 years of LE among eastern German women versus -0.10 years among western German women.

As a consequence of these changes in LE at birth, the LE gaps between western and eastern Germany increased between 2019 and 2020 (see Fig. 1). Among men, the gap now amounts to 1.50 years in favour of western Germany (1.28 years in 2019). Such a large difference was last observed 20 years previously, in 2000. Among women, the west-east difference, which had been fluctuating around zero for around a decade, reversed again in favour of the West and now amounts to 0.10 years (2019: -0.05 years). For the population as a whole (both sexes combined), the difference in LE between western and eastern Germany increased to 0.86 years (2019: 0.66 years).

As a further consequence of the changes in LE at birth, the differences in LE between women and men increased in 2020 compared with 2019. The gender gap in LE is now 4.84 years in favour of women in Germany as a whole (2019: 4.72 years), 4.57 years in western Germany (2019: 4.47 years) and 5.97 years in eastern Germany 
Tab. 1: Life expectancy at birth and at age 65 (by sex) for Germany as a whole, eastern Germany and western Germany in 2019 and 2020

\begin{tabular}{lrrrrrr}
\hline & \multicolumn{2}{c}{ Year 2019 } & \multicolumn{2}{c}{ Year 2020 } & \multicolumn{2}{c}{ Difference 2019-2020 } \\
& At birth & At age 65 & At birth & At age 65 & At birth & At age 65 \\
\hline Germany as a whole & & & & & & \\
$\quad$ Both sexes & 81.21 & 19.77 & 81.01 & 19.55 & -0.20 & -0.22 \\
Women & 83.56 & 21.27 & 83.43 & 21.11 & -0.13 & -0.16 \\
Men & 78.84 & 18.10 & 78.60 & 17.84 & -0.24 & -0.26 \\
Eastern Germany & & & & & & \\
Both sexes & 80.66 & 19.67 & 80.31 & 19.27 & -0.36 & -0.40 \\
Women & 83.60 & 21.38 & 83.35 & 21.09 & -0.25 & -0.29 \\
Men & 77.79 & 17.75 & 77.38 & 17.28 & -0.41 & -0.47 \\
Western Germany & & & & & & \\
Both sexes & 81.33 & 19.79 & 81.17 & 19.62 & -0.16 & -0.17 \\
Women & 83.55 & 21.25 & 83.45 & 21.12 & -0.10 & -0.13 \\
Men & 79.08 & 18.18 & 78.88 & 17.98 & -0.19 & -0.20 \\
Difference between sexes & & & & & & \\
Germany as a whole & 4.72 & 3.18 & 4.84 & 3.27 & +0.11 & +0.09 \\
Eastern Germany & 5.80 & 3.63 & 5.97 & 3.80 & +0.17 & +0.18 \\
Western Germany & 4.47 & 3.07 & 4.57 & 3.14 & +0.10 & +0.07 \\
West-east difference & & & & & & \\
Both sexes & 0.66 & 0.13 & 0.86 & 0.35 & +0.20 & +0.22 \\
Women & -0.05 & -0.13 & 0.10 & 0.03 & +0.15 & +0.16 \\
Men & 1.28 & 0.43 & 1.50 & 0.69 & +0.22 & +0.26 \\
\hline
\end{tabular}

Source: Own calculations with data from the Federal Statistical Office.

(2019: 5.80 years). However, the increase in the differences in LE between sexes was slightly smaller than the increase in inequality between eastern and western Germany ( +0.11 vs. +0.20 years).

Between 2019 and 2020, the decrease in LE at age 65 was greater than the decrease in LE at birth for both sexes and in all regions (see Table 1). This indicates that it was mainly the older age groups that were affected by the increase in mortality in 2020. Figure 2 shows the results of the decomposition of changes in LE between 2019 and 2020 into the contributions of 5-year age groups (exceptions: single age 0-1 and last open age interval $100+$ ). The results of the decomposition analysis confirm that it was mostly older age groups that contributed to the decrease in LE. Among men, the mortality increase started at around age 65 in Germany as a whole and in western Germany, and at a slightly younger age (around 60 ) in eastern Germany. Mortality among the younger age groups (0-30 years) remained almost constant in Germany as a whole and in western Germany. In contrast, there was a decrease in mortality among men in eastern Germany of the same ages between 2019 and 2020. 
Fig. 1: Difference in life expectancy (LE) at birth and at age 65 between western and eastern Germany, 2000-2020

LE at birth

West-east difference

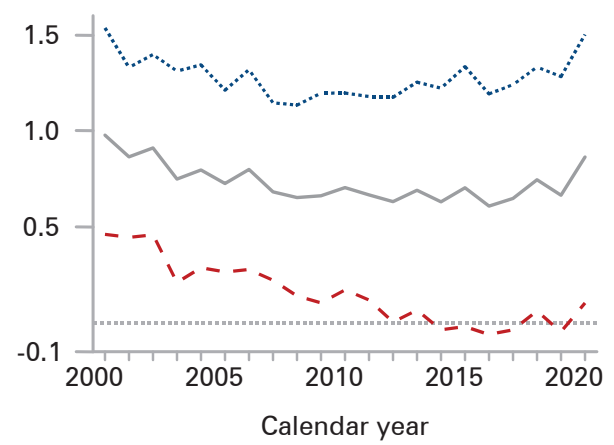

LE at age 65

West-east difference

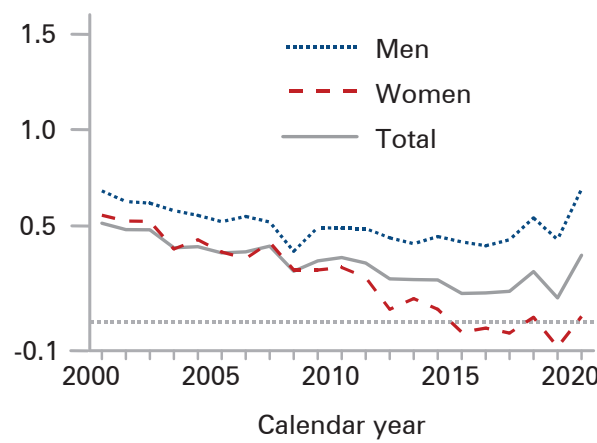

Source: Own calculations with data from the Federal Statistical Office.

Women show smaller age-specific contributions than man, which is in line with their smaller decreases in LE. However, women do not only differ in terms of the magnitude of the LE decrease, but also in terms of the age pattern. Compared with men, the changes in LE were due in larger part to increased mortality in older ages (around ages 75+ for Germany as a whole and for western Germany). The pattern for women in eastern Germany differs slightly, however. First, and similar to what was described for men, the mortality increase started at slightly younger ages (in this case around 65). Second, girls born in eastern Germany experienced a higher level of infant mortality in 2020 compared with 2019, contributing about -0.03 years to the difference in LE. Table 2 summarises the described age-specific contributions to differences in LE for Germany as a whole, eastern Germany, and western Germany for the broader age groups 0-29, 30-64 and 65+.

Finally, we examine the effect of the pandemic on mortality in Germany in another statistic frequently derived from period life tables: lifespan inequality. As can be seen in Table 3, the decrease in LE in 2020 was accompanied by a small decrease in lifespan inequality (of -0.09 years, from 9.93 years to 9.84 years), which was of a similar magnitude for both women and men, but stronger in eastern than in western Germany. In keeping with the changes observed in LE, men in eastern Germany experienced the largest decrease in lifespan inequality at birth $(-0.23$ years). For western German men, the decline in lifespan inequality was only -0.10 years. Among women, the decline in lifespan inequality was also greater in former East Germany than in former West Germany: -0.16 years among eastern German women versus -0.08 years among western German women. The fact that lifespan inequality decreased in 2020 as against a year earlier is due to the increase in mortality affecting predominantly the younger elderly. This in turn led to a stronger concentration of deaths in this age segment and thus to a reduced variation in ages at death. This is also reflected in the fact that the decrease in lifespan inequality at 
Fig. 2: Age decomposition of differences in life expectancy (LE) at birth between 2019 and 2020 in Germany as a whole, eastern Germany and western Germany, by sex

\section{Germany as a whole}

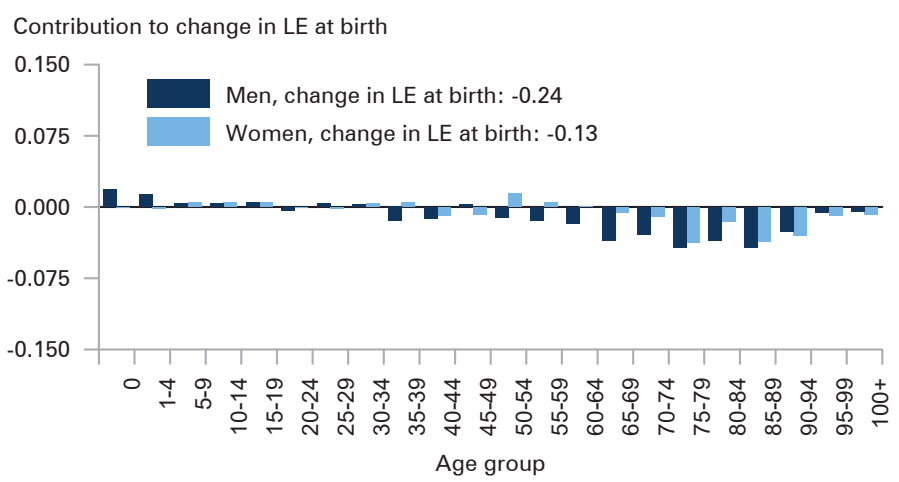

Eastern Germany

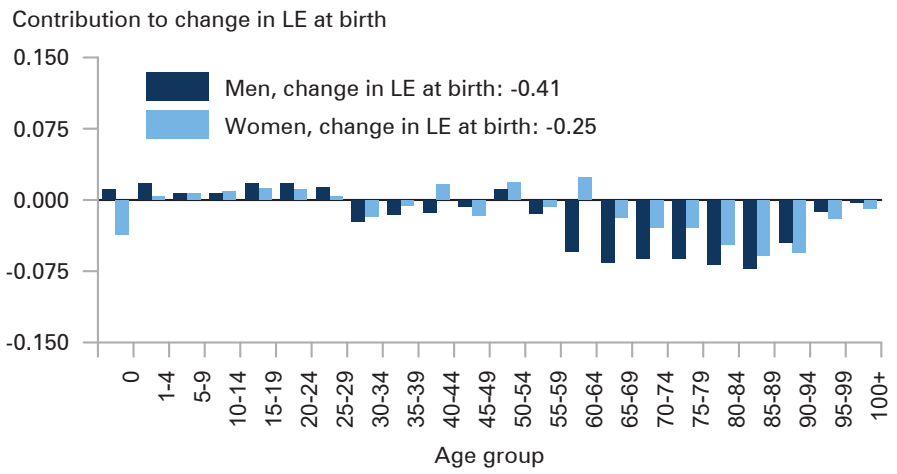

Western Germany

Contribution to change in LE at birth

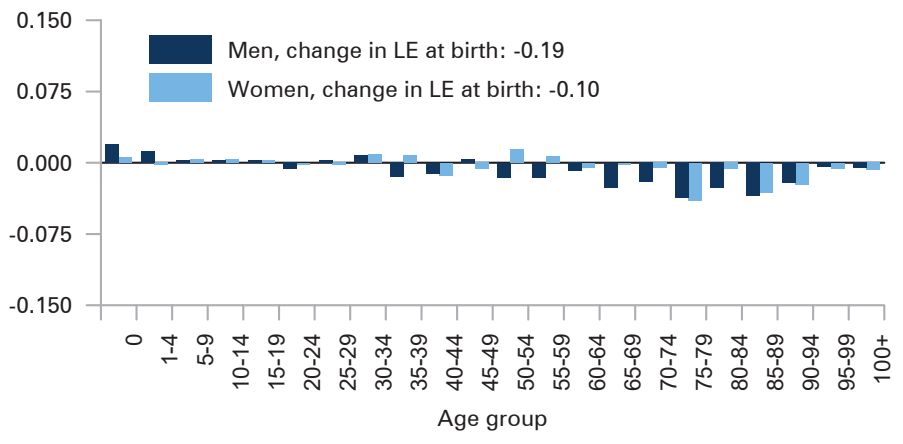

Source: Own calculations with data from the Federal Statistical Office. 
Tab. 2: Contribution of changes in mortality in selected age groups to changes in life expectancy at birth between 2019 and 2020

\begin{tabular}{lcccc}
\hline & \multicolumn{3}{c}{ Contribution by age group } & \\
& $0-29$ & $30-64$ & $65+$ & Total change \\
\hline $\begin{array}{l}\text { Germany as a whole } \\
\quad \text { Women }\end{array}$ & +0.01 & +0.01 & -0.15 & \\
$\quad$ Men & +0.04 & -0.06 & -0.22 & -0.13 \\
Eastern Germany & & & & -0.24 \\
$\quad$ Women & +0.01 & +0.01 & -0.27 & -0.25 \\
$\quad$ Men & +0.09 & -0.11 & -0.39 & -0.41 \\
Western Germany & & & & -0.10 \\
$\quad$ Women & +0.01 & +0.01 & -0.12 & -0.19 \\
$\quad$ Men & +0.04 & -0.05 & -0.18 & \\
\hline
\end{tabular}

Source: Own calculations with data from the Federal Statistical Office.

ages $65+$ was similar to the changes in lifespan inequality at birth for both sexes and in all regional groups.

The varying extents of changes in lifespan inequality led to some interesting consequences regarding the differences between eastern and western Germany. Whereas in 2019, women in western Germany were characterised by only slightly higher lifespan inequality as against eastern German women (higher by 0.05 years), the gap increased to 0.13 years in 2020 . The opposite can be observed for men: inequality in the lifespans of western German men was lower than that of eastern German men. In 2019, the west-east gap in lifespan inequality was of more than half a year $(-0.56)$ before decreasing to -0.43 in 2020 .

\section{$4 \quad$ Summary and discussion}

Differences in mortality between eastern and western Germany have been a longstanding topic for demographic research. These are rooted in varying health experiences during the period prior to reunification which were caused by differing economic, social, medical, and environmental contexts in the two parts of Germany, resulting in excess mortality in eastern Germany that persisted until long after reunification and the adoption of the western health care system in the territory of the former GDR (Kibele 2012; Diehl 2008; Gjonça et al. 2000; Luy 2004; Simon 2005). Although the gap in LE between the two regions has been narrowing rapidly since reunification, mortality has not converged in a uniform manner for both sexes and has also differed between age groups and causes of death (Nolte et al. 2000, 2001; Vogt et al. 2017). In addition, overall living conditions in eastern regions remained persistently worse relative to western Germany, indicating that current eastern-western differentials are still relevant when it comes to explaining mortality 
Tab. 3: $\quad$ Lifespan inequality at birth and at age 65 (by sex) for Germany as a whole, eastern Germany, and western Germany in 2019 and 2020

\begin{tabular}{lrrrrrr}
\hline & \multicolumn{2}{c}{ Year 2019} & \multicolumn{2}{c}{ Year 2020 } & \multicolumn{2}{c}{ Difference 2019-2020 } \\
& At birth & At age 65 & At birth & At age 65 & At birth & At age 65 \\
\hline Germany as a whole & & & & & & \\
$\quad$ Both sexes & 9.93 & 7.34 & 9.84 & 7.27 & -0.10 & -0.08 \\
$\quad$ Women & 9.04 & 6.97 & 8.94 & 6.89 & -0.10 & -0.07 \\
$\quad$ Men & 10.42 & 7.45 & 10.30 & 7.35 & -0.12 & -0.10 \\
Eastern Germany & & & & & & \\
$\quad$ Both sexes & 10.23 & 7.36 & 10.06 & 7.23 & -0.17 & -0.14 \\
$\quad$ Women & 9.00 & 6.87 & 8.84 & 6.74 & -0.16 & -0.13 \\
$\quad$ Men & 10.88 & 7.52 & 10.65 & 7.33 & -0.23 & -0.18 \\
Western Germany & & & & & & \\
$\quad$ Both sexes & 9.87 & 7.34 & 9.79 & 7.27 & -0.08 & -0.06 \\
$\quad$ Women & 9.05 & 6.99 & 8.97 & 6.93 & -0.08 & -0.06 \\
$\quad$ Men & 10.32 & 7.43 & 10.22 & 7.35 & -0.10 & -0.09 \\
Difference between sexes & & & & & & \\
$\quad$ Germany as a whole & 1.39 & 0.49 & 1.37 & 0.46 & -0.02 & -0.03 \\
$\quad$ Eastern Germany & 1.88 & 0.65 & 1.81 & 0.60 & -0.07 & -0.05 \\
$\quad$ Western Germany & 1.27 & 0.44 & 1.26 & 0.42 & -0.01 & -0.02 \\
West-east difference & & & & & & \\
$\quad$ Both sexes & -0.37 & -0.02 & -0.28 & +0.05 & +0.09 & +0.07 \\
$\quad$ Women & +0.05 & +0.12 & +0.13 & +0.20 & +0.07 & +0.07 \\
$\quad$ Men & -0.56 & -0.08 & -0.43 & 0.02 & +0.13 & +0.10 \\
\hline
\end{tabular}

Source: Own calculations with data from the Federal Statistical Office.

patterns, and have increasingly gained scientific and political awareness (Luy 2006; Razum et al. 2008; Shkolnikov et al. 2008). As a result of these ongoing differences, the COVID-19 pandemic was likely to have a different effect on mortality in the two parts of the country.

Even though the extent of the decrease in LE in 2020 was only minor in Germany compared with other countries, our results indicate that the increase in mortality between 2019 and 2020 did indeed follow different patterns in eastern and western Germany. This finding suggests that the impact of the COVID-19 pandemic on LE and lifespan inequality was not the same in the two parts of Germany. The biggest decrease in LE at birth was experienced by men in eastern Germany ( -0.41 years). For men in western Germany, the decline in LE was less pronounced ( -0.19 years). Similarly, among women, the decline in LE was also greater in eastern Germany $(-0.25$ years) than in western Germany $(-0.10$ years). As a consequence of these changes, the gap in LE between western and eastern Germany increased to a level that was last observed in the year 2000. Even though these differences also affected 
the gap in LE between women and men for Germany as a whole, the increase in differences in LE between sexes was smaller than the increase in differences between eastern and western Germany.

In addition, our decomposition of LE into age-specific contributions showed that LE at age 65 decreased more strongly than LE at birth for both sexes and in both regions from 2019 to 2020 . This underlines the fact that older age groups were those accounting most for the increase in mortality in 2020, whereas younger individuals experienced constant or even slightly lower mortality levels in 2020 (at least partly because of a lower number of accidents due to lockdown measures). The age at which the increase in old age mortality began was slightly earlier in men than in women. In accordance with these changes in age-specific mortality, the changes in lifespan inequality also differed between women and men, and between western and eastern Germany. Because eastern German women and men were affected by the mortality increase among the younger elderly more than their western counterparts, lifespan inequality decreased to a greater extent for both sexes in this part of the country. The decrease in lifespan inequality among both sexes in all regions confirms the findings from studies for other countries that also found a decrease in lifespan inequality between 2019 and 2020 as a consequence of the COVID-19 pandemic (e.g. Aburto et al. 2021a). Note, however, that the fact that lifespans became more equal during the COVID-19 pandemic should not be interpreted as a positive change in mortality. It instead reflects the shift of deaths from older to younger elderly with the resulting decrease in the variation of ages at death. As a result, ages at death became more homogenous, but in a negative way, because more people died at a younger age.

In light of the comparatively small mortality changes in Germany in 2020, the difficult data issue regarding Berlin (for which population and death data are no longer published separately for former East and West Berlin by the Federal Statistical Office) is a noteworthy limitation of this study. As described in the data section, we assigned the population and deaths in Berlin to eastern and western Germany simply by the calendar year-specific proportions of the current population in the former territories of East and West Berlin, thus assuming that mortality is identical in the two parts of the German capital. Although internal and external migration has seen a considerable mixing of the populations in East and West Berlin following reunification, there are several reasons why this assumption might be incorrect, one being the continuing difference in age structures and socioeconomic conditions. However, the possible bias caused by this assumption can be neglected for western Germany because of West Berlin's low proportion in the population as a whole (around 5 percent for both the living population and deaths in 2020). The corresponding proportion for eastern Germany is higher (around 25 percent for the living population and around 20 percent for deaths in 2020), but comparisons of our LE estimates with those of the HMD, which carried out more detailed reconstructions of the data for former East and West Berlin until 2017, shows only minor deviations (for 2017, our estimates are only 0.01 years higher for women and 0.10 years lower for men). Similarly, the estimates of e-dagger - the lifespan inequality measure applied in this study - are lower in our data only by 0.01 years for eastern German women 
and higher by 0.05 years for eastern German men in 2017, compared with those based on the HMD (data not shown). Nonetheless, it may be the case that these deviations apply similarly to 2020 , possibly making the relatively small differences between eastern and western German men even smaller.

It should be noted again, however, that the reductions in LE observed in Germany are much smaller relative to other countries such as the US, Russia, Spain, and Belgium (Andrasfay/Goldman 2021; Aburto et al. 2021b/c). This is likely to be a result of the strict prevention and social support measures imposed by the government. Since the differences in LE decreases that we are seeing are relatively small for the most part (e.g. -0.25 years for women in eastern Germany vs. -0.10 years for women in western Germany), statistical randomness should be considered when interpreting our results. More specifically, deviations in LE trends that lay in the range of about 0.10 to 0.20 years may have occurred at random.

Furthermore, neither the western nor the eastern German population is homogenous. It has been shown, for example, that Saxony experienced the strongest decline in LE while Mecklenburg-Western Pomerania is one of the regions where changes in LE between 2019 and 2020 have been the smallest (BiB 2021). In this sense, readers should be aware that the results presented in this study refer to average values for territories with substantial heterogeneity. In addition to differences between eastern and western Germany in terms of mortality deterioration during the COVID-19 pandemic, there is also empirical evidence for a north-south gradient (BiB 2021; Zur Nieden/Engelhart 2021). This suggests that differences in recent LE trends cannot be fully explained by the health differentials that persist between eastern and western Germany. Likewise, the incidence of infection in neighbouring countries is likely to play a role as well. A proper assessment of the reasons for the observed LE differences is, however, beyond the scope of this study.

Finally, it should be noted that a decline in LE between two calendar years and the magnitude of the decline observed in 2020 are not exceptional (see Fig. 3). For instance, LE decreased in 2015 in all regions and for both genders as well. The magnitude of this reduction was even greater in 2015, but other population groups were affected. Whereas in 2020 increased levels of mortality were greater among men than women, the decrease in 2015 was stronger among women. With regard to the west-east differences in 2015, eastern Germany displayed a disadvantage in the younger age groups, while mortality in the upper age groups increased mainly in western Germany (data not shown). The mortality increase in 2020 was obviously related to the COVID-19 pandemic. In contrast, the causes of increasing mortality levels in 2015 are still unclear (Luy et al. 2020).

To conclude, the most important finding of our analysis of the changes in mortality in 2020 is that increases in mortality rates due to COVID-19 were not uniform across eastern and western Germany. The population in eastern Germany was hit harder, with a greater increase in mortality which started in younger ages than in western Germany and, consequently, a greater reduction in LE. Further research is necessary to assess which factors are associated to these persistent differences between eastern and western Germany, and what the most likely policy implications are in terms of mitigating these effects in future. 
Fig. 3: Annual change in life expectancy (LE) at birth and at age 65 in eastern Germany, western Germany and Germany as a whole, 2010-2020

Men

Change in LE at birth

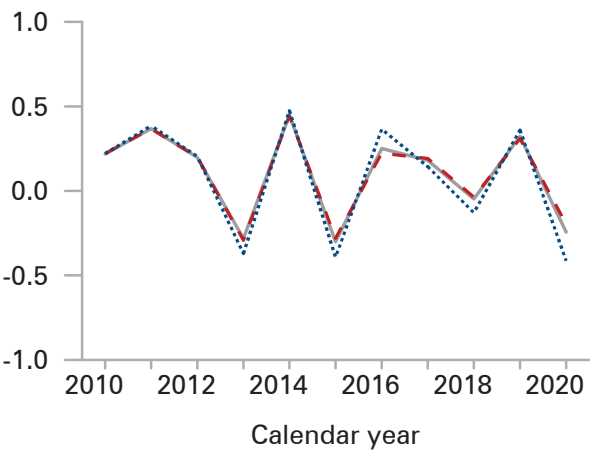

Men

Change in LE at age 65

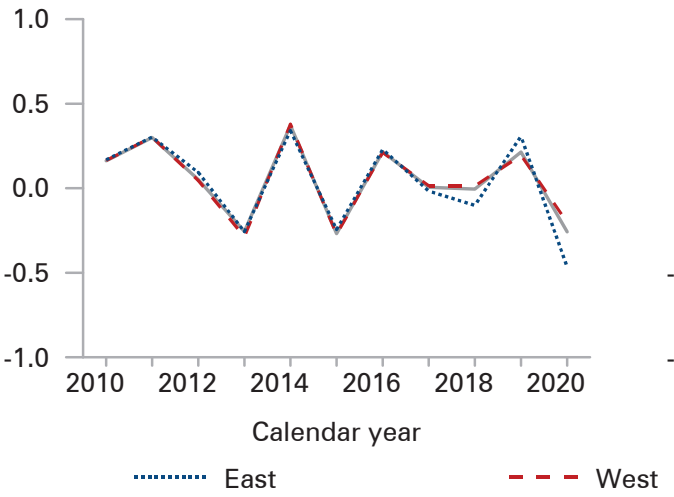

Women

Change in LE at birth

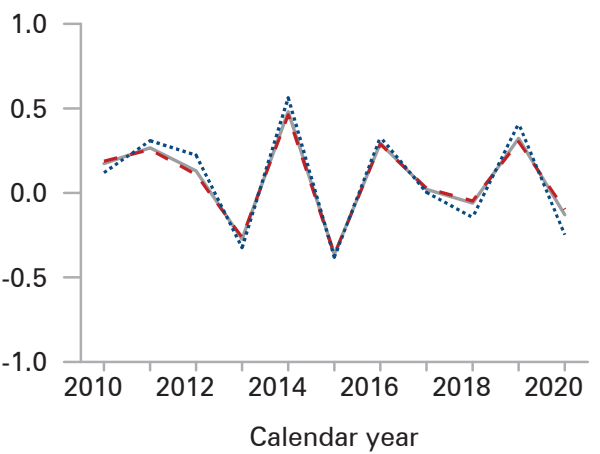

Women

Change in LE at age 65

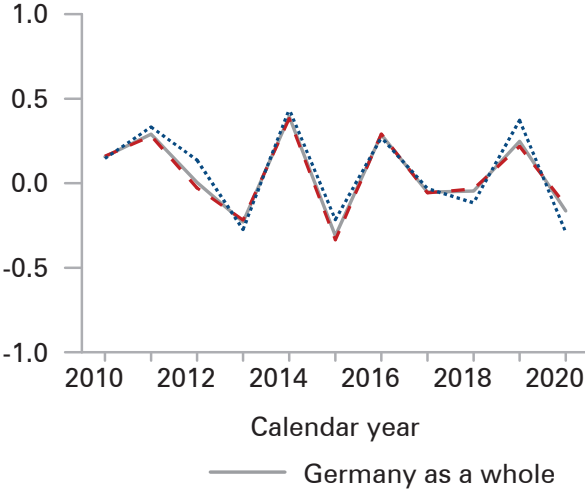

Note: The numbers refer to the changes in LE as against the previous year.

Source: Own calculations with data from the Federal Statistical Office.

\section{References}

Aburto, José Manuel et al. 2021a: Estimating the burden of the COVID-19 pandemic on mortality, life expectancy and lifespan inequality in England and Wales: A populationlevel analysis. In: Journal of Epidemiology and Community Health 75: 735-740. https://doi.org/10.1136/jech-2020-215505

Aburto, José Manuel et al. 2021b: Quantifying impacts of the COVID-19 pandemic through life-expectancy losses: a population-level study of 29 countries. In: International Journal of Epidemiology 9. https://doi.org/10.1093/ije/dyab207

Aburto, José Manuel et al. 2021c: Life expectancy declines in Russia during the COVID-19 pandemic in 2020. https://doi.org/10.31219/osf.io/7cuvy 
Andrasfay, Theresa; Goldman, Noreen 2021: Reductions in 2020 US life expectancy due to COVID-19 and the disproportionate impact on the Black and Latino populations. In: PNAS 118,5: e2014746118. https://doi.org/10.1073/pnas.2014746118

Arriaga, Eduardo E. 1984: Measuring and explaining the change in life expectancy. In: Demography 21,1: 83-96. https://doi.org/10.2307/2061029

Beaney, Thomas et al. 2020: Excess mortality: the gold standard in measuring the impact of COVID-19 worldwide? In: Journal of the Royal Society of Medicine 113,9: 329-334. https://doi.org/10.1177/0141076820956802

Bhopal, Sunil S.; Bhopal, Raj 2020: Sex differential in COVID-19 mortality varies markedly by age. In: Lancet Correspondence 396,10250: 532-533. https://doi.org/10.1016/S0140-6736(20)31748-7

BiB 2021: COVID-19: Lebenserwartung in Deutschland im internationalen Vergleich nur gering gesunken. Bundesinstitut für Bevölkerungswissenschaften. Press release from the 12th of October 2021 [https://www.bib.bund.de/DE/Service/Presse/2021/2021 10-12-COVID-19-Lebenserwartung-in-Deutschland-im-internationalen-Vergleich-nurgering-gesunken.html, 10.11.2021].

Diehl, Katharina 2008: Mögliche Faktoren für die rasche Reduktion der ostdeutschen Übersterblichkeit nach der Wiedervereinigung. Warum leben Ostdeutsche seit der Wiedervereinigung länger? In: Zeitschrift für Bevölkerungswissenschaft 33,1: 89-110. https://doi.org/10.1007/s12523-008-0006-x

Eurostat 2021: Life expectancy decreased in 2020 across the EU. Eurostat database [https://ec.europa.eu/eurostat/web/products-eurostat-news/-/edn-20210407-1, 01.09.2021].

Gebhard, Catherine et al. 2020: Impact of sex and gender on COVID-19 outcomes in Europe. In: Biology of Sex Differences 11: 29. https://doi.org/10.1186/s13293-020-00304-9

Ghis/andi, Simone et al. 2021: Human costs of the first wave of the COVID-19pandemic in the major epicentres in Italy. In: Vienna Yearbook of Population Research: 1-32. https://doi.org/10.1553/populationyearbook2022.res2.1

Gjonça, Arjan; Brockmann, Hilke; Maier, Heiner 2000: Old-age mortality in Germany prior to and after reunification. In: Demographic Research 3,1. https://doi.org/10.4054/DemRes.2000.3.1

Grigoriev, Pave/et al. 2021: 30 Jahre Deutsche Einheit: Errungenschaften und verbliebene Unterschiede in der Mortalitätsentwicklung nach Alter und Todesursachen (30 years of German unification: achievements and remaining differences in mortality trends by age and cause of death.) In: Bundesgesundheitsblatt, Gesundheitsforschung, Gesundheitsschutz 64;4: 481-490. https://doi.org/10.1007/s00103-021-03299-9

HMD (Human Mortality Database) 2021: University of California, Berkeley (USA), and Max Planck Institute for Demographic Research (Germany) [www.mortality.org, 01.09.2021].

Islam, Nazrul et al. 2021: Excess deaths associated with covid-19 pandemic in 2020: age and sex disaggregated time series analysis in 29 high income countries. In: BMJ 373:n1137. https://doi.org/10.1136/bmj.n1137

Karanikolos Marina; McKee, Martin 2020: European Observatory on Health Systems and Policies. How comparable is COVID-19 mortality across countries? In: Eurohealth 26,2: 45-50.

Kibele, Eva U.B. 2012: Regional mortality differences in Germany. Dordrecht: Springer Science \& Business Media. https://doi.org/10.1007/978-94-007-4432-5 
Kontis, Vasilis et al. 2020: Magnitude, demographics and dynamics of the effect of the first wave of the COVID-19 pandemic on all-cause mortality in 21 industrialized countries. In: Nature Medicine 27. https://doi.org/10.1038/s41591-021-01254-4

Luy, Marc 2004: Mortality differences between western and eastern Germany before and after reunification. A macro and micro level analysis of developments and responsible factors. In: Genus 60,3-4: 99-141.

Luy, Marc 2006: Mortality tempo-adjustment: An empirical application. In: Demographic Research 15,21: 561-590. https://dx.doi.org/10.4054/DemRes.2006.15.21

Luy, Marc et al. 2020: Life expectancy: frequently used, but hardly understood. In: Gerontology 66,1: 95-104. https://doi.org/10.1159/000500955

Modig, Karin; Ahlbom, Anders; Ebeling, Marcus 2021: Excess mortality from COVID-19: Weekly excess death rates by age and sex for Sweden and its most affected region. In: European Journal of Public Health 31,1: 17-22. https://doi.org/10.1093/eurpub/ckaa218

Nolte, Ellen; Shkolnikov, Vladimir; McKee, Martin 2000: Changing mortality patterns in East and West Germany and Poland. I: Long term trends (1960-1997). In: Journal of Epidemiology and Community Health 54,12: 890-898. https://doi.org/10.1136/jech.54.12.890

Nolte, Ellen; Koupilová, Ilona; McKee, Martin 2001: Temporal and spatial pattern of infant mortality in Germany after unification. In: Sozial- und Präventivmedizin 46,5: 303-310. https://doi.org/10.1007/BF01321081

Olsen, Sonja J. et al. 2021: Changes in Influenza and Other Respiratory Virus Activity During the COVID-19 Pandemic - United States, 2020-2021. In: Morbidity and Mortality Weekly Report 70,29: 1013-1019. https://doi.org/10.15585/mmwr.mm7029a1

Preston, Samuel H.; Heuveline, Patrick; Guillot, Michel 2001: Demography: Measuring and modeling population processes. Blackwell Publishing.

Razum, Oliver et al. 2008: Social epidemiology after the German reunification: East vs. West or poor vs. rich? In: International Journal of Public Health 53,1: 13-22. https://doi.org/10.1007/s00038-007-6116-8

Sauerberg, Markus 2021: Das Mortalitätsgeschehen während der COVID-19-Pandemie in Deutschland und anderen europäischen Ländern. In: Lines, Emily (Ed.): PostPandemic Populations: Die soziodemografischen Folgen der COVID-19-Pandemie in Deutschland. Discussion Paper No. 13. Berlin: Max Planck Society/Population Europe.

Shkolnikov, Vladimir M. et al. 2008: Length of life and the pensions of five million retired German men. In: European Journal of Public Health 18,3: 264-269. https://doi.org/10.1093/eurpub/ckm102

Shkolnikov, Vladimir M. et al. 2011: Losses of expected lifetime in the United States and other developed countries: methods and empirical analyses. In: Demography 48,1: 211-239. https://doi.org/10.1007/s13524-011-0015-6

Simon, Michael 2005: Das Gesundheitssystem in Deutschland. Eine Einführung in Struktur und Funktionsweise. Bern/Göttingen/Toronto/Seattle: Verlag Hans Huber 2005: Das Gesundheitssystem in Deutschland. Eine Einführung in Struktur und Funktionsweise. Bern/Göttingen/Toronto/Seattle: Verlag Hans Huber.

Statistisches Bundesamt 2021: Sterbefälle und Lebenserwartung: Periodensterbetafeln für Deutschland. Statistisches Bundesamt [https://www.destatis.de/DE/Themen/ Gesellschaft-Umwelt/Bevoelkerung/Sterbefaelle-Lebenserwartung/ inhalt.html, 01.09.2021]. 
Trias-Llimós, Sergi; Riffe, Tim; Bilal, Usama 2020: Monitoring life expectancy levels during the COVID-19 pandemic: Example of the unequal impact of the first wave on Spanish regions. In: PLoS ONE 15,11:e0241952. https://doi.org/10.1371/journal.pone.0241952

Van Raalte, Alyson A.; Caswell, Hal 2013: Perturbation analysis of indices of lifespan variability. In: Demography 50,5: 1615-1640. https://doi.org/10.1007/s13524-013-0223-3

Vandoros, Sotiris 2020: Excess mortality during the Covid-19 pandemic: Early evidence from England and Wales. In: Social Science \& Medicine 258,113101. https://doi.org/10.1016/j.socscimed.2020.113101

Vaupel, James W.; Zhang, Zhen; van Raalte, Alyson A. 2011: Life expectancy and disparity: an international comparison of life table data. In: BMJ open 1,1:e000128. https://doi.org/10.1136/bmjopen-2011-000128

Vaupel, James W.; Canudas-Romo, Vladimir 2003: Decomposing change in life expectancy: A bouquet of formulas in honor of Nathan Keyfitz's 90th birthday. In: Demography 40,2: 201-216. https://doi.org/10.1353/dem.2003.0018

Vigezzi, Serena et al. 2021: Divergent Trends of Lifespan Variation During Mortality Crises. In: SocArXiv. https://doi.org/10.31235/osf.io/ze57r

Vogt, Tobias et al. 2017: The German East-West Mortality Difference: Two Crossovers Driven by Smoking. In: Demography 54,3: 1051-1071. https://doi.org/10.1007/s13524-017-0577-z

Zhang, Zhen; Vaupel, James W. 2009: The age separating early deaths from late deaths. In: Demographic Research 20: 721-730. https://dx.doi.org/10.4054/DemRes.2009.20.29

Zur Nieden, Felix; Engelhart, Alexander 2021: Sterbefallzahlen und Übersterblichkeit während der Corona-Pandemie. Statistisches Bundesamt: Wirtschaft und Statistik, Ausgabe 3/2021.

Dr. Marc Luy ( $\varangle)$; Markus Sauerberg, Ph.D.; Magdalena Muszyńska-Spielauer, Ph.D.; Vanessa di Lego, Ph.D. Vienna Institute of Demography (OeAW), Wittgenstein Centre for Demography and Global Human Capital (IIASA, OeAW, University of Vienna). Vienna, Austria.

E-mail: mail@marcluy.eu, markus.sauerberg@oeaw.ac.at, magdalena.muszynska@oeaw.ac.at, Vanessa.DiLego@oeaw.ac.at

URL: https://marcluy.eu https://www.oeaw.ac.at/vid/people/staff/markus-sauerberg https://www.oeaw.ac.at/vid/people/staff/magdalena-muszynska-spielauer https://www.oeaw.ac.at/vid/people/staff/vanessa-di-lego 


\section{Appendix}

Fig. A1: Proportions of the estimated total average populations of western and eastern Berlin

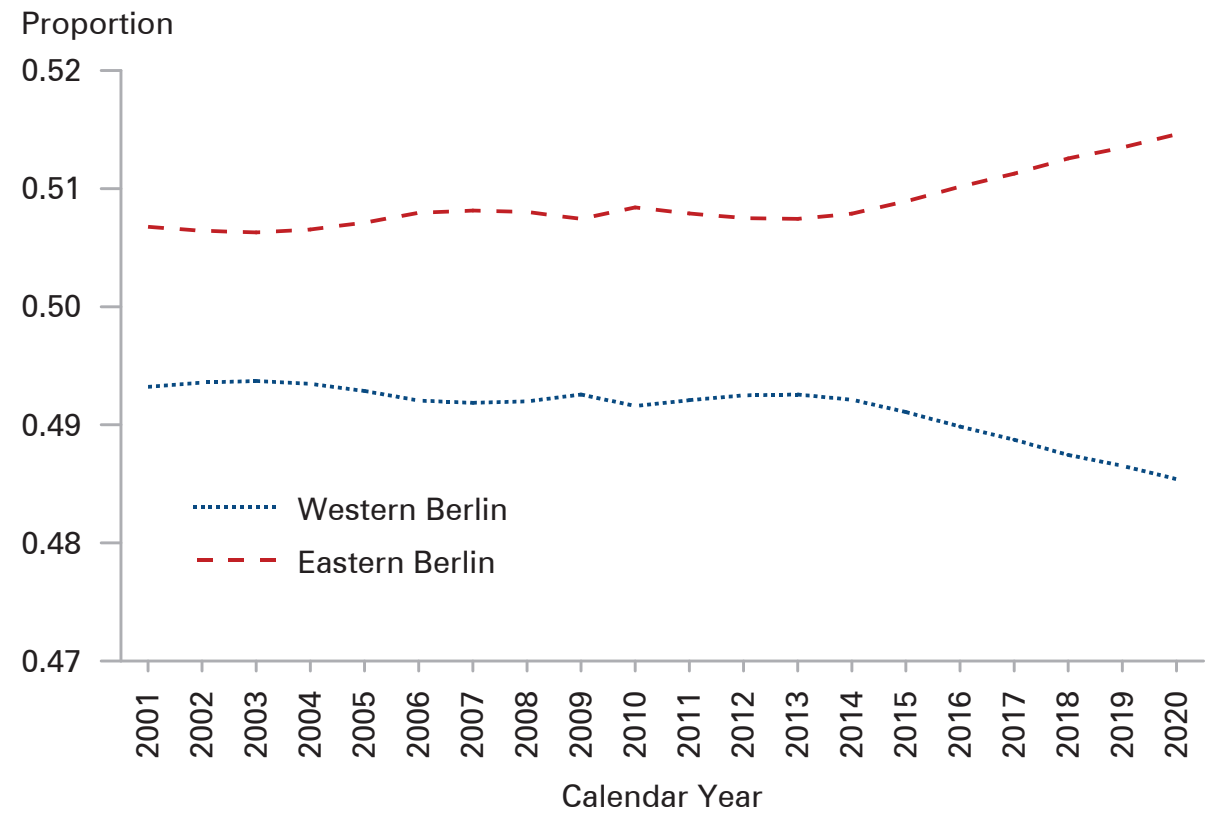

Source: own calculations with data of the statistical office Berlin-Brandenburg. 
Fig. A2: Relative change in the number of deaths by age for women and men in western and eastern Germany, 2001-2020 (2001=1.0)

(a) Western Germany, men

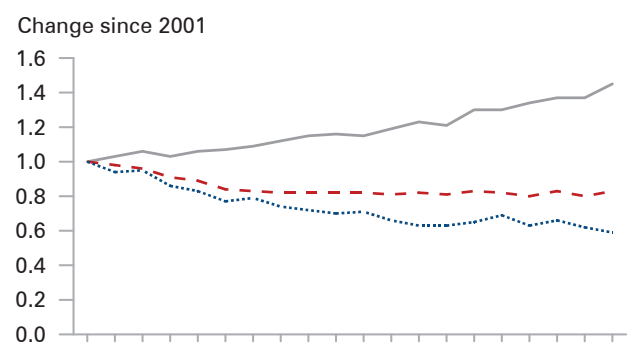

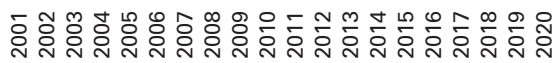
Calendar year

(c) Western Germany, women Change since 2001

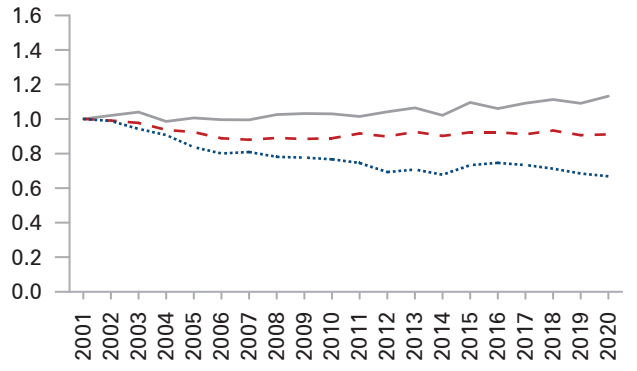

Calendar year (b) Eastern Germany, men

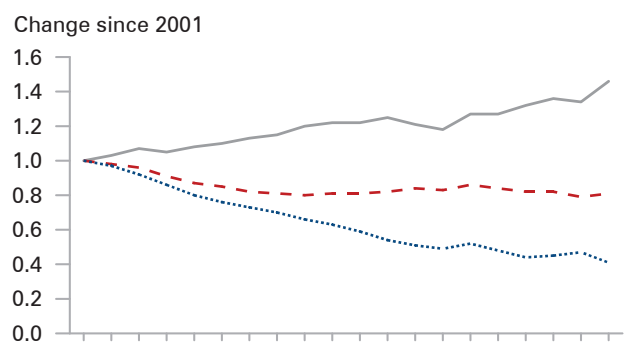

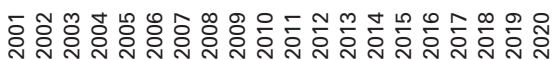
Calendar year

(d) Eastern Germany, women

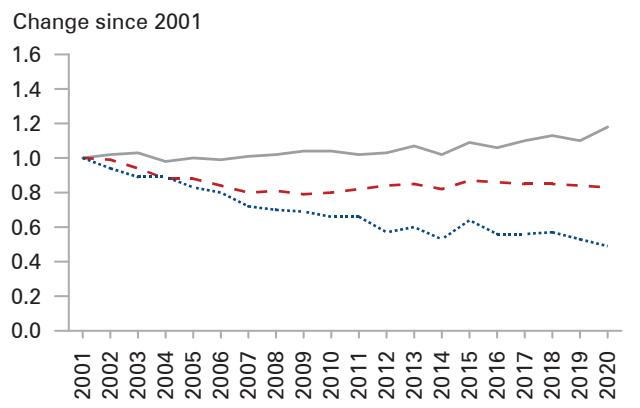

Calendar year

.......... Age 0-29 - - - Age 30-64 Age 65+

Source: own calculations with data of the Federal Statistical Office. 


\section{Comparative Population Studies}

WWW.comparativepopulationstudies.de

ISSN: 1869-8980 (Print) - 1869-8999 (Internet)

\section{Published by}

Prof. Dr. Norbert F. Schneider

Federal Institute for Population Research D-65180 Wiesbaden / Germany

\section{(c) BY-SA}

2021

\section{Managing Editor}

Prof. Dr. Johannes Huinink

Dr. Katrin Schiefer

\section{Editorial Assistant}

Beatriz Feiler-Fuchs

Wiebke Hamann

\section{Layout}

Beatriz Feiler-Fuchs

E-mail:cpos@bib.bund.de

\section{Scientific Advisory Board}

Karsten Hank (Cologne)

Michaela Kreyenfeld (Berlin)

Marc Luy (Vienna)

Natalie Nitsche (Rostock)

Zsolt Spéder (Budapest)

Rainer Wehrhahn (Kiel)

\section{Board of Reviewers}

Bruno Arpino (Barcelona)

Kieron Barclay (Rostock)

Laura Bernardi (Lausanne)

Gabriele Doblhammer (Rostock)

Anette Eva Fasang (Berlin)

Michael Feldhaus (Oldenburg)

Tomas Frejka (Sanibel)

Alexia Fürnkranz-Prskawetz (Vienna)

Birgit Glorius (Chemnitz)

Fanny Janssen (Groningen)

Frank Kalter (Mannheim)

Stefanie Kley (Hamburg)

Bernhard Köppen (Koblenz)

Anne-Kristin Kuhnt (Duisburg)

Hill Kulu (St Andrews)

Nadja Milewski (Wiesbaden)

Roland Rau (Rostock)

Thorsten Schneider (Leipzig)

Tomas Sobotka (Vienna)

Jeroen J. A. Spijker (Barcelona)

Heike Trappe (Rostock)

Helga de Valk (The Hague)

Sergi Vidal (Barcelona)

Michael Wagner (Cologne) 